\title{
Production of Complex Molecules in Astrophysical Ices
}

\author{
Marla H. Moore ${ }^{1}$ and Reggie L. Hudson ${ }^{2}$ \\ ${ }^{1}$ Astrochemistry Laboratory, NASA/Goddard Space Flight Center, \\ Greenbelt, MD 20771, USA \\ email: Marla.H.Moore@nasa.gov \\ ${ }^{2}$ Department of Chemistry, Eckerd College, \\ St. Petersburg, FL 33711, USA, \\ email: hudsonrl@eckerd.edu
}

\begin{abstract}
The inventory of interstellar and solar system molecules now numbers well over 100 species, including both ions and neutrals. Gas-phase formation routes to many of the observed organics are still uncertain, so that solid-phase syntheses are of interest. Low-temperature reactions are thought to occur within interstellar ices, on ice and grain surfaces in the interstellar medium (ISM), and on icy surfaces of solar system objects (e.g., Europa, Pluto). Ionizing radiation, such as cosmic rays, and far-UV photons are two possible initiators of such chemistry.

In the Cosmic Ice Lab at NASA's Goddard Space Flight Center, we can study both the photo- and radiation-induced chemistries of ices at 8-300 K. Our most-recent work has been motivated by the detections of ethylene glycol, $\mathrm{HOCH}_{2} \mathrm{CH}_{2} \mathrm{OH}$, in the ISM (Hollis et al. 2002) and in comet Hale-Bopp (Crovisier et al. 2002). Ethylene glycol is currently the largest firmlyidentified cometary molecule as well as one of the larger interstellar organics. It's formation and accompanying chemistry provide challenges and tests for current astrochemical thought.

Here we discuss laboratory experiments on ethylene glycol's solid-phase formation and destruction. Using infrared spectroscopy, we have identified low-temperature radiation-chemical pathways that lead from known interstellar ices, such as either $\mathrm{CH}_{3} \mathrm{OH}$ or $\mathrm{H}_{2} \mathrm{O}$ and $\mathrm{CO}$, to ethylene glycol. We also have identified a role for ethylene glycol in the formation of glycolaldehyde, $\mathrm{HOCH}_{2} \mathrm{C}(\mathrm{O}) \mathrm{H}$, a simple sugar (Hollis, Lovas, \& Jewell 2000). Related to these results are the 6- and 7-atom molecules formed by oxidation and reduction processes in irradiated $\mathrm{H}_{2} \mathrm{O}+$ $\mathrm{C}_{2} \mathrm{H}_{2}$ ices. Analogous experiments have been conducted on two other triply-bonded molecules in $\mathrm{H}_{2} \mathrm{O}$-rich ice, $\mathrm{HCN}$ and $\mathrm{N}_{2}$. An important focus of our work is the development of reaction schemes for the formation of complex molecules within astrochemically-relevant ices, and the use of such schemes to predict new molecules awaiting detection.
\end{abstract}

Keywords. astrobiology — astrochemistry — ISM: abundances — ISM: molecules - methods: laboratory - molecular processes

\section{Introduction}

The current inventory of interstellar (IS) and solar system molecules now numbers well over a hundred species including inorganics, organics, ions, and radicals. The most complex molecule has thirteen atoms. Of the stable organics, half can be considered nitrile and acetylene derivatives, with the other half being aldehydes, alcohols, ethers, acids, ketones, amides, and related molecules. Ethylene glycol, $\mathrm{HOCH}_{2} \mathrm{CH}_{2} \mathrm{OH}$, is composed of ten atoms, and is the most complex organic identified in both comet Hale-Bopp (Crovisier et al. 2002) and IS environments (Hollis et al. 2000). Table 1 lists observed interstellar and circumstellar organic molecules, with cometary species indicated by underlining.

Although a variety of astrochemical problems can be approached successfully through gas-phase chemistry, efficient syntheses for many interstellar and cometary organics are 
Table 1. Organic molecules observed in interstellar and circumstellar regions. A few related inorganic molecules are included.

Hydrocarbons and Simple Hydrides, Oxides, and Sulfides

\begin{tabular}{llll}
$\underline{\mathrm{CH}_{4}}$ & $\underline{\mathrm{H}_{2} \mathrm{O}}$ & $\frac{\mathrm{NH}_{3}}{\mathrm{~N}_{2} \mathrm{O}}$ & $\underline{\underline{\mathrm{CO}}}$ \\
$\mathrm{C}_{2} \mathrm{H}_{4} \mathrm{~S}$ & $\underline{\mathrm{CO}}$ \\
\hline & $\underline{\mathrm{CO}_{2}}$ & $\mathrm{~N}_{2}$ & $\underline{\mathrm{OCS}}$
\end{tabular}

Nitriles, Alkynes, and Related Molecules

\begin{tabular}{|c|c|c|c|}
\hline $\mathrm{CH}_{3} \mathrm{CN}$ & $\underline{\mathrm{HCN}}$ & $\underline{\mathrm{HNC}}$ & $\mathrm{C}_{2} \mathrm{H}_{2}$ \\
\hline $\mathrm{CH}_{3}(\mathrm{CC}) \mathrm{CN}$ & $\mathrm{H}(\overline{\mathrm{CC}}) \mathrm{CN}$ & $\overline{\mathrm{CH}_{3} \mathrm{NC}}$ & $\mathrm{H} \overline{(\mathrm{CC})_{2}} \mathrm{H}$ \\
\hline $\mathrm{CH}_{3}(\mathrm{CC})_{2} \mathrm{CN}$ & $\overline{\mathrm{H}(\mathrm{CC})_{2} \mathrm{CN}}$ & $\mathrm{HCCNC}$ & $\mathrm{H}(\mathrm{CC})_{3} \mathrm{H}$ \\
\hline $\mathrm{CH}_{2} \mathrm{CHCN}$ & $\mathrm{H}(\mathrm{CC})_{3} \mathrm{CN}$ & & $\mathrm{CH}_{3}(\mathrm{CC}) \mathrm{H}$ \\
\hline $\mathrm{CH}_{3} \mathrm{CH}_{2} \mathrm{CN}$ & $\begin{array}{l}\mathrm{H}(\mathrm{CC})_{4} \mathrm{CN} \\
\mathrm{H}(\mathrm{CC})_{5} \mathrm{CN}\end{array}$ & $\mathrm{NH}_{2} \mathrm{CN}$ & $\mathrm{CH}_{3}(\mathrm{CC})_{2} \mathrm{H}$ \\
\hline
\end{tabular}

\begin{tabular}{|c|c|c|c|}
\hline \multicolumn{4}{|c|}{ Organics and Related Molecules } \\
\hline $\mathrm{H}_{2} \mathrm{CO}$ & $\mathrm{CH}_{3} \mathrm{OH}$ & $\underline{\mathrm{HCOOH}}$ & $\mathrm{CH}_{2} \mathrm{CO}$ \\
\hline $\mathrm{HC}(\mathrm{O}) \mathrm{CH}_{3}$ & $\mathrm{CH}_{2} \mathrm{CH}(\mathrm{OH})$ & $\overline{\mathrm{CH}_{3} \mathrm{COOH}}$ & \\
\hline $\mathrm{H}_{3} \overline{\mathrm{C}-\mathrm{CH}_{2}-\mathrm{C}(\mathrm{O}) \mathrm{H}}$ & $\mathrm{CH}_{3} \mathrm{CH}_{2} \mathrm{OH}$ & & $\mathrm{HNCO}$ \\
\hline $\begin{array}{c}\mathrm{H}_{2} \mathrm{C}=\mathrm{CH}-\mathrm{C}(\mathrm{O}) \mathrm{H} \\
\mathrm{HCCH}-\mathrm{C}(\mathrm{O}) \mathrm{H}\end{array}$ & $\underline{\mathrm{HOCH}_{2} \mathrm{CH}_{2} \mathrm{OH}}$ & $\mathrm{HC}(\mathrm{O}) \mathrm{OCH}_{3}$ & HNCS \\
\hline $\mathrm{HOCH}_{2} \mathrm{C}(\mathrm{O}) \mathrm{H}$ & $c-\mathrm{C}_{2} \mathrm{H}_{4} \mathrm{O}$ & $\mathrm{HC}(\mathrm{O}) \mathrm{NH}_{2}$ & $\mathrm{H}_{2} \mathrm{CS}$ \\
\hline$\left(\mathrm{CH}_{3}\right)_{2} \mathrm{CO}$ & $\left(\mathrm{CH}_{3}\right)_{2} \mathrm{O}$ & $\begin{array}{c}\mathrm{CH}_{2} \mathrm{NH} \\
\mathrm{CH}_{3} \mathrm{NH}_{2}\end{array}$ & $\overline{\mathrm{CH}_{3} \mathrm{SH}}$ \\
\hline
\end{tabular}

still unknown, so that solid-phase reactions are of interest. Among the gas-phase interstellar observations in which solid-phase chemistry has been invoked are those involving formaldehyde, $\mathrm{H}_{2} \mathrm{CO}$ (Federmann \& Allen 1991); methanol, $\mathrm{CH}_{3} \mathrm{OH}$ (e.g., Charnley et al . 1995; Tielens \& Whittet 1997; Teixeira et al. 1998); acetic acid, $\mathrm{CH}_{3} \mathrm{COOH}$ (Mehringer et al. 1997); ethylene oxide, $c-\mathrm{C}_{2} \mathrm{H}_{4} \mathrm{O}$ (Nummelin et al. 1998); methylenimene, $\mathrm{CH}_{2} \mathrm{NH}$ (Dickens et al. 1997); ethyl cyanide, $\mathrm{CH}_{3} \mathrm{CH}_{2} \mathrm{CN}$ (Miao \& Synder 1997); vinyl alcohol, $\mathrm{CH}_{2} \mathrm{CH}\left(\mathrm{OH}\right.$ ) (Turner \& Apponi, 2001); ethylene glycol, $\mathrm{HOCH}_{2} \mathrm{CH}_{2} \mathrm{OH}$ (Hollis et al. 2002); glycolaldehyde, $\mathrm{HOCH}_{2} \mathrm{C}(\mathrm{O}) \mathrm{H}$ (Hollis et al. 2000); propenal, $\mathrm{CH}_{2} \mathrm{CHC}(\mathrm{O}) \mathrm{H}$; and propanal, $\mathrm{CH}_{3} \mathrm{CH}_{2} \mathrm{C}(\mathrm{O}) \mathrm{H}$ (Hollis et al. 2004).

One way in which organics can be formed in space is through chemical reactions occurring within the icy mantles of interstellar grains. Reactions can be initiated by either particle radiation or high-energy photons, resulting in the synthesis of new molecular species which can then be ejected into the gas phase by various mechanisms (e.g., Bringa \& Johnson 2004, and references therein). Possible evidence for energetic processing within IS ices is the $\mathrm{OCN}^{-}$ion (Hudson et al. 2001), while evidence for energetic processing in solar system ices comes from identifications of $\mathrm{H}_{2} \mathrm{O}_{2}, \mathrm{O}_{2}$, and $\mathrm{O}_{3}$ on Galilean moons. In comets, as with many interstellar regions, it is the many detections of gas-phase species that imply an active ice chemistry. In all cases, the importance of solid-phase reactions will depend on parameters such as initial ice composition, radiation flux, exposure time, temperature, and competing reactions.

Table 2 gives estimates of radiation and photon fluxes and doses for ices in both IS and solar system environments. Galactic cosmic rays are estimated to be about $87 \%$ protons, $12 \%$ helium nuclei, and $1 \%$ heavier nuclei, with an overall isotropic flux assumed constant for the age of the solar system, $4.6 \times 10^{9}$ years. Since the IS electron cosmic-ray flux is 10-100 times smaller than the proton flux, for energies below $100 \mathrm{MeV}$ the cosmic-ray processing of IS ices is dominated by protons whose greatest intensity lies in the low 


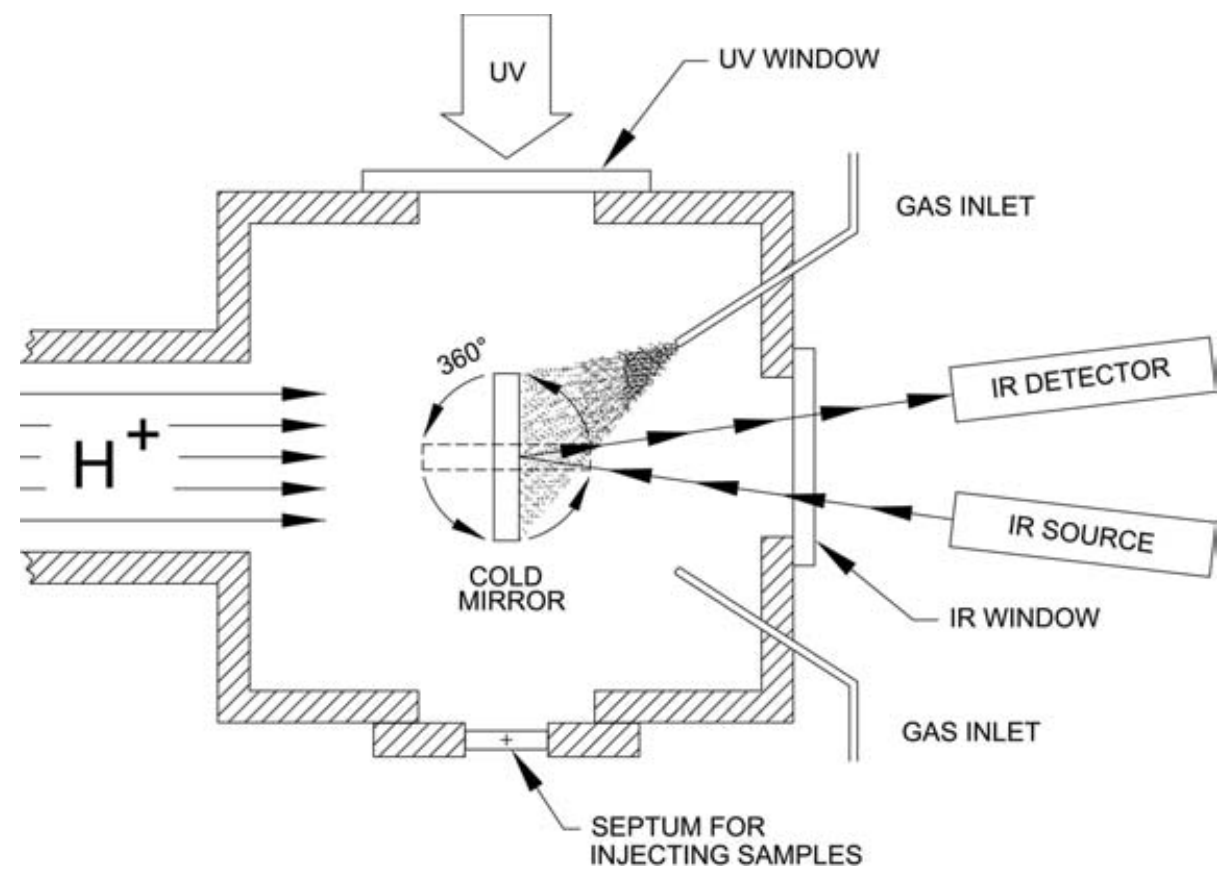

Figure 1. Schematic of laboratory set-up.

$\mathrm{MeV}$ range, with an energy spectrum decreasing with a power-law index of 2.5 at higher energies. The estimated energy dose from cosmic ray protons is $\sim 0.3 \mathrm{eV}$ molecule ${ }^{-1}$ over $10^{6}$ years, the approximate lifetime of a molecular cloud. Within this same time, $\sim 0.4 \mathrm{eV}$ molecule ${ }^{-1}$ is deposited from UV photons that exist within dense cloud regions. Most of these IS photons are produced by hot $\mathrm{O}$ and $\mathrm{B}$ type stars, whose estimated abundance gives a calculated UV flux of $9.6 \times 10^{8} \mathrm{eV} \mathrm{cm}^{-2} \mathrm{~s}^{-1}$ between 91 and $180 \mathrm{~nm}$.

The final products of photon- and radiation-induced chemical reactions within ices can be, and typically are, identical, but the processes by which they are made are quite different. The energy of a $1 \mathrm{MeV}$ proton is deposited in an ice along a track containing numerous excitations and ionizations, with the concomitant production of thousands of secondary electrons causing most of the observed chemical changes. In contrast, each vacuum-UV photon is absorbed in a single excitation or ionization event. For comparison, in a $1 \mathrm{~g} \mathrm{~cm}^{-3} \mathrm{H}_{2}$ O-ice the range of a $1 \mathrm{MeV}$ proton is $\sim 20 \mu \mathrm{m}$, while there is a $37 \%$ drop in UV transmission in $0.15 \mu \mathrm{m}$, for a UV cross-section of $2 \times 10^{-18} \mathrm{~cm}^{2}$ (Okabe 1978).

In our lab we synthesize complex organics in cosmic-ice analogs, with reactions initiated by either high-energy protons $(\sim 1 \mathrm{MeV})$, to mimic cosmic rays, or vacuum-UV photons. We systematically vary reaction doses, temperatures, abundances of both minor and major (matrix) materials, and ice thickness. We also routinely employ isotopic labeling and isoelectronic systems to identify reaction products and test promising mechanisms. This approach allows us to understand and predict new interstellar molecules, and to identify processes and products that less comprehensive strategies would miss.

For this paper we describe the synthesis of complex organics from three triply-bonded molecules: carbon monoxide $(\mathrm{C} \equiv \mathrm{O})$, acetylene $(\mathrm{HC} \equiv \mathrm{CH})$, and hydrogen cyanide $(\mathrm{HC} \equiv \mathrm{N})$. These unsaturated, isoelectronic, linear molecules are all highly-reactive, and all are detected in both IS and solar system environments. These three species are the starting point for making about twenty different molecules, radicals, and ions where, for $\mathrm{CO}$ and $\mathrm{C}_{2} \mathrm{H}_{2}$, the primary syntheses are based on reactions of $\mathrm{H}$ and $\mathrm{OH}$ radicals; for $\mathrm{HCN}$ the 
Table 2. Estimated UV photon and $1 \mathrm{MeV}$ proton fluxes in different regions of space, and doses experienced by ices.

\begin{tabular}{|c|c|c|c|c|c|}
\hline \multirow[b]{2}{*}{ Region } & \multirow{2}{*}{$\begin{array}{c}\text { Residence } \\
\text { Time of } \\
\text { Ices in } \\
\text { Region } \\
\text { (years) }\end{array}$} & \multicolumn{2}{|c|}{$\mathrm{UV}^{a}$} & \multicolumn{2}{|c|}{ Cosmic Ray Protons $^{a}$} \\
\hline & & \begin{tabular}{|c|} 
Flux \\
$10 \mathrm{eV}$ \\
photon \\
$\mathrm{eV} \mathrm{cm}^{-2} \mathrm{~s}^{-1}$ \\
\end{tabular} & $\begin{array}{l}\text { Energy Dose } \\
\mathrm{eV} \text { molecule }\end{array}$ & $\begin{array}{c}\text { Flux } \\
1 \mathrm{MeV} \text { proton } \\
\mathrm{eV} \mathrm{cm}^{-2} \mathrm{~s}^{-1}\end{array}$ & $\begin{array}{l}\text { Energy Dose } \\
\mathrm{eV} \text { molecule }\end{array}$ \\
\hline $\begin{array}{l}\text { IS Cold Dense } \\
\text { Cloud } \\
(0.02 \mu \mathrm{m} \text { ice })\end{array}$ & $\begin{array}{l}10^{6} \\
10^{7}\end{array}$ & $1.4 \times 10^{4}$ & $\begin{array}{c}0.4 \\
4\end{array}$ & $1 \times 10^{6}$ & $\begin{array}{c}0.3 \\
3\end{array}$ \\
\hline $\begin{array}{l}\text { Oort Cloud } \\
\text { and } \\
\text { KBO Region }\end{array}$ & $4.6 \times 10^{9}$ & $9.6 \times 10^{8}$ & $\begin{array}{c}10^{8} \\
\text { (top } 0.015 \mu \mathrm{m} \\
\text { layer) }\end{array}$ & $\begin{array}{c}\text { Energy } \\
\text { dependent flux } \\
\phi(\mathrm{E})\end{array}$ & $\begin{array}{c}150(0.1 \mathrm{~m}) \\
5(5 \mathrm{~m})\end{array}$ \\
\hline $\begin{array}{c}\text { Jovian } \\
\text { Satellites } \\
\text { e.g., Europa }\end{array}$ & $<1 \times 10^{8}$ & $4 \times 10^{13}$ & $\begin{array}{c}10^{13} \\
\text { (top } 0.015 \mu \mathrm{m} \\
\text { layer) }\end{array}$ & $\begin{array}{c}\text { Magnetospheric } \\
\text { ions } \\
7.8 \times 10^{13}\end{array}$ & $\begin{array}{c}150\left(1 \mathrm{~cm}, 10^{4}\right. \\
\text { years })\end{array}$ \\
\hline $\begin{array}{l}\text { Typical Lab } \\
\text { Experiment }\end{array}$ & $4.6 \times 10^{-4}$ & $8.6 \times 10^{14}$ & 14 & $7 \times 10^{10}$ & 9 \\
\hline
\end{tabular}

Notes: ${ }^{a}$ Energy dose for UV and cosmic ray protons for the IS medium is from Moore et al. (2001); for the Oort cloud, KBO and Jovian satellite regions from Moore et al. (2003) and references therein. ${ }^{b}$ Possible resurfacing lifetime from Stern and McKinnon (2000).

primary observed reaction path is oxidation of the cyano (-CN) functional group. Here we highlight radiation experiments in which we have identified the infrared (IR) signatures of complex species in $\mathrm{H}_{2} \mathrm{O}$-rich ices containing $\mathrm{CO}, \mathrm{C}_{2} \mathrm{H}_{2}$, or $\mathrm{HCN}$. Since actual cosmic ices are not simple binary systems, we have also had to consider the roles played by other molecules and reactions, such as the formation of ions through acid-base chemistry with $\mathrm{NH}_{3}$. Finally, our results for these simple systems permit predictions of yet undetected, and more complex, organic molecules in comets and IS space.

\section{Laboratory Methods}

Details of our experimental set-up, ice preparation, IR spectral measurements, cryostat, and proton beam source have been published (Moore \& Hudson 2000; Moore \& Hudson 1998). Figure 1 is a schematic that represents an ice sample within our sample chamber. Briefly, ices were formed by condensation of gas-phase mixtures onto a precooled aluminum mirror at $10-20 \mathrm{~K}$, where mid-IR spectra $\left(4000-400 \mathrm{~cm}^{-1}\right)$ of ices were taken by reflection from the mirror. Ices were $1-5 \mu \mathrm{m}$ thick, as determined by a laser interference fringe system. Samples temperatures were controlled from 10 to $300 \mathrm{~K}$ with a heater on the cryostat tail section.

IR spectra were recorded before and after exposure of ice samples to a $0.8 \mathrm{MeV}$ proton beam from a Van de Graaff accelerator. The use of proton irradiation to simulate cosmicray bombardment has been discussed earlier (e.g., Hudson \& Moore, 2001; Moore et al. 
1983). Since sample ice thicknesses were less than the range of the incident $0.8 \mathrm{MeV}$ protons, the bombarding ions penetrated the ices and came to rest in the underlying metal substrate, not in the ices themselves. Radiation doses were determined by counting the proton fluence $\left(\mathrm{p}^{+} \mathrm{cm}^{-2}\right)$ at the ice, and converting to a common scale of eV (18-amu molecule $)^{-1}$. Proton stopping powers and ranges were calculated with Ziegler's SRIM program (Ziegler et al. 1985; http://www.srim.org).

\section{Laboratory Studies of Unsaturated Carbon-Containing Species in $\mathrm{H}_{2} \mathrm{O}$-Rich Ices}

\subsection{Study of $\mathrm{CO}$ in $\mathrm{H}_{2} \mathrm{O}$ Ice}

To make a complex organic molecule, a laboratory chemist selects a simpler starting material and performs reactions such as those of addition or substitution of atoms or functional groups. In cometary and IS ices, carbon monoxide trails only $\mathrm{H}_{2} \mathrm{O}$ in abundance, and so is a likely source of solid-phase organic chemistry. The $\mathrm{H}_{2} \mathrm{O}$-ice itself, subject to ionizing radiation, is a ready source of $\mathrm{H}$ atoms, $\mathrm{OH}$ radicals, $\mathrm{H}_{2} \mathrm{O}^{+}$, and $\mathrm{e}^{-}$. These reactive species are available to participate in reactions such as $\mathrm{H}_{2} \mathrm{O}_{2}$ formation, protonation by $\mathrm{H}_{2} \mathrm{O}^{+}\left(\right.$or $\left.\mathrm{H}_{3} \mathrm{O}^{+}\right), \mathrm{OH}$ radical addition, and reduction by $\mathrm{e}^{-}$. The possibility that such chemistry might take place in astronomical ices is at least 10 years old (Tielens \& Allamandola 1987; Mumma et al. 1996), and probably much older.

Reaction Scheme 1 summarizes the laboratory irradiations of $\mathrm{H}_{2} \mathrm{O}+\mathrm{CO}$ ices (Hudson \& Moore 1999), where brackets indicate presumed but unobserved products. Radiation processing of $\mathrm{H}_{2} \mathrm{O}+\mathrm{CO}$ mixtures formed $\mathrm{HCO}, \mathrm{H}_{2} \mathrm{CO}$, and $\mathrm{CH}_{3} \mathrm{OH}$ through $\mathrm{H}$-addition, and formic acid $(\mathrm{HCOOH})$ in a branching reaction step. In addition, $\mathrm{CO}_{2}$ was efficiently made by $\mathrm{O}$-atom transfer from $\mathrm{OH}$ radicals to $\mathrm{CO}$. Figure 2 shows the IR spectrum, in the $1900-1000 \mathrm{~cm}^{-1}$ region, of an $\mathrm{H}_{2} \mathrm{O}+\mathrm{CO}$ (5:1) ice after irradiation to $11 \mathrm{eV}$ molecule ${ }^{-1}$ at $16 \mathrm{~K}$. Bands of $\mathrm{H}_{2} \mathrm{CO}, \mathrm{CH}_{3} \mathrm{OH}$, and $\mathrm{HCOOH}$ in this region are identified by comparison with reference spectra of dilute mixtures of each of molecule in $\mathrm{H}_{2} \mathrm{O}$-ice. The HCO radical is at $1853 \mathrm{~cm}^{-1}$. Similar experiments were performed at other $\mathrm{H}_{2} \mathrm{O} / \mathrm{CO}$ ratios (Hudson \& Moore 1999) and in the presence of $\mathrm{NH}_{3}$ (Hudson et al. 2001).

One of the most important findings from these experiments was the relatively high percentage of conversion of $\mathrm{CO}$ into other molecules. After about $22 \mathrm{eV}$ molecule ${ }^{-1}$, for an ice whose initial $\mathrm{H}_{2} \mathrm{O} / \mathrm{CO}$ ratio was 5 , the conversion of $\mathrm{CO}$ into $\mathrm{CO}_{2}$ was $\sim 20 \%$, $\mathrm{HCOOH} \sim 40 \%, \mathrm{H}_{2} \mathrm{CO} \sim 7 \%$ and $\mathrm{CH}_{3} \mathrm{OH} \sim 9 \%$. These percentages are a function of the initial $\mathrm{CO}$ abundance and radiation dose, and are calculated by knowing the integrated band strengths of each molecule and assuming an ice density (see Hudson \& Moore 1999).

A comparison of our results with hydrogenation experiments of Watanabe et al. (2003, 2004 ) is shown in Figure 3. In their experiments, the source of $\mathrm{H}$ atoms was a cold atomic hydrogen beam simulating the emplacement of $\mathrm{H}$-atoms onto IS ice grain mantles in cold dark clouds. Hydrogenation of $\mathrm{H}_{2} \mathrm{O}+\mathrm{CO}$ (4:1) ices resulted in production of both

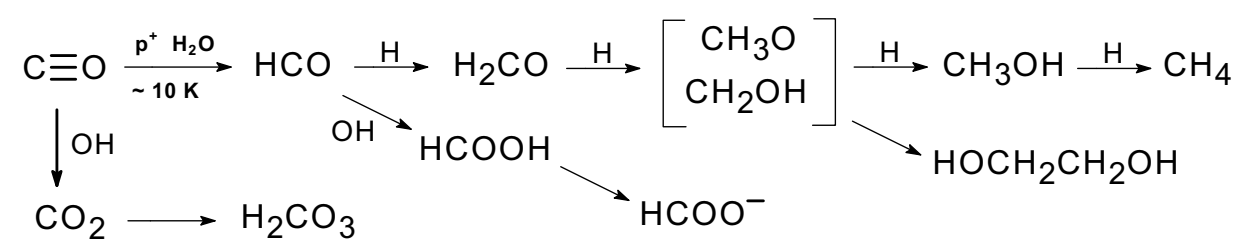

REACTION SCHEME 1 


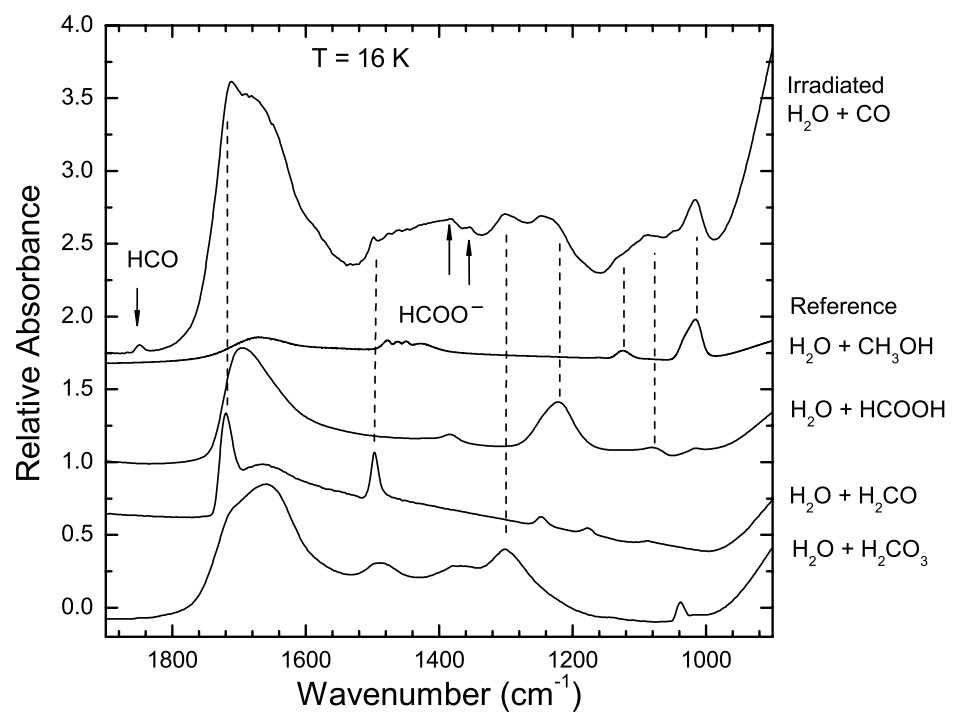

Figure 2. New species formed in an $\mathrm{H}_{2} \mathrm{O}+\mathrm{CO}(5: 1)$ ice irradiated to $11 \mathrm{eV}$ molecule ${ }^{-1}$ are identified by comparison with reference spectra of dilute mixtures of organics at $\sim 16 \mathrm{~K}$. Spectra are offset for clarity.

$\mathrm{H}_{2} \mathrm{CO}$ and $\mathrm{CH}_{3} \mathrm{OH}$. Watanabe et al. $(2003,2004)$ assumed a $10^{4}-10^{6}$ year exposure to an $\mathrm{H}$-atom density of $1 \mathrm{~cm}^{-3}$ at $10 \mathrm{~K}$. Ratios of column densities of $\mathrm{CO} / \mathrm{CH}_{3} \mathrm{OH}$ and $\mathrm{H}_{2} \mathrm{CO} / \mathrm{CH}_{3} \mathrm{OH}$ are plotted in Figure 3. The left-hand data point is equivalent to $10^{6}$ years, and the right-hand data point to $10^{4}$ years (based on Watanabe et al. 2004, Figure 5). Our results are plotted to show data representing exposure of an $\mathrm{H}_{2} \mathrm{O}+\mathrm{CO}$ (5:1) ice to $\sim 1,10$, and $22 \mathrm{eV}$ molecule ${ }^{-1}$ corresponding to cosmic-ray proton exposure for $3 \times 10^{6}, 3 \times 10^{7}$, and $7 \times 10^{7}$ years in a dense $10 \mathrm{~K}$ cloud. Both types of experiments appear able to convert $\mathrm{CO}$ to $\mathrm{H}_{2} \mathrm{CO}$ and $\mathrm{CH}_{3} \mathrm{OH}$ at levels comparable to those detected in cometary comae and interstellar ices. Note, however, that the rate of conversion of $\mathrm{CO}$ by $\mathrm{H}$ atoms is still controversial (Hiraoka et al. 2002, 2005).

\subsection{1. $\mathrm{CH}_{3} \mathrm{OH}$ as a Starting Point for Ethylene Glycol Formation}

Once formed, $\mathrm{CH}_{3} \mathrm{OH}$ can undergo other reactions to make more complex molecules. Results from our experiments on $\mathrm{H}_{2} \mathrm{O}+\mathrm{CH}_{3} \mathrm{OH}$ ice (3:1) showed that after irradiation at $16 \mathrm{~K}, \mathrm{CO}, \mathrm{CO}_{2}, \mathrm{HCO}, \mathrm{H}_{2} \mathrm{CO}, \mathrm{HCOO}^{-}$, and ethylene glycol $\left(\mathrm{HOCH}_{2} \mathrm{CH}_{2} \mathrm{OH}\right)$ are present (Hudson \& Moore 2000a). Figure 4 shows the sample's IR spectra before and after irradiation. Absorptions at $1088 \mathrm{~cm}^{-1}$ (peak) and $1046 \mathrm{~cm}^{-1}$ (shoulder) are matched with a reference spectrum of ethylene glycol. This molecule's formation is explained by straightforward chemistry in which hydroxymethyl radicals $\left(\mathrm{CH}_{2} \mathrm{OH}\right)$, produced by proton irradiation of $\mathrm{CH}_{3} \mathrm{OH}$, couple to make $\mathrm{HOCH}_{2} \mathrm{CH}_{2} \mathrm{OH}$ (see Reaction Scheme 1).

\subsubsection{Relationship Between Ethylene Glycol and Glycolaldehyde}

Recently we reported the solid-phase synthesis of glycolaldehyde $\left[\mathrm{HOCH}_{2} \mathrm{C}(\mathrm{O}) \mathrm{H}\right]$ in irradiated ices containing ethylene glycol, both with and without $\mathrm{H}_{2} \mathrm{O}$ (Hudson et al. 2005). This reaction is consistent with other aldehyde-alcohol interconversions we have studied, such as for $\left[\mathrm{H}_{2} \mathrm{CO}, \mathrm{CH}_{3} \mathrm{OH}\right],\left[\mathrm{CH}_{3} \mathrm{C}(\mathrm{O}) \mathrm{H}, \mathrm{CH}_{3} \mathrm{CH}_{2} \mathrm{OH}\right]$ pairs (Hudson \& Moore 2001). Figure 5 shows the spectral changes of ethylene glycol ice during proton irradiation. 


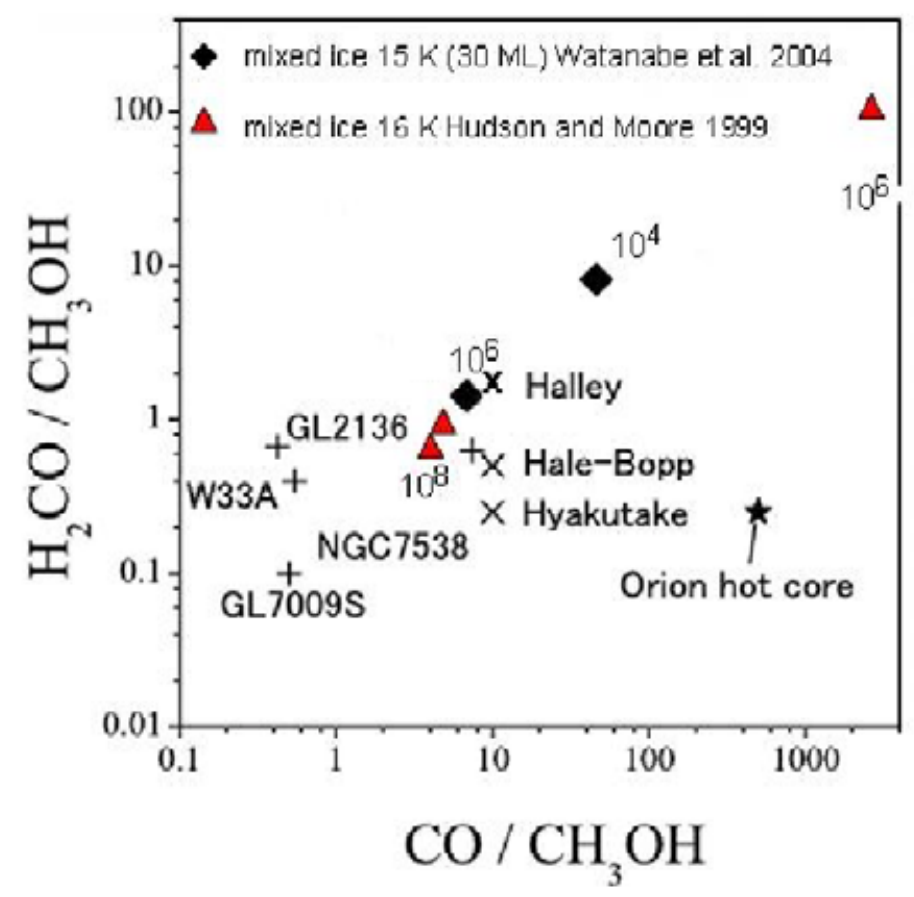

Figure 3. Abundance ratios of $\mathrm{H}_{2} \mathrm{CO}$ and $\mathrm{CO}$, relative to $\mathrm{CH}_{3} \mathrm{OH}$, are compared for hydrogenation results of Watanabe et al. (2004) on $\mathrm{H}_{2} \mathrm{O}+\mathrm{CO}(4: 1)$ ice at $15 \mathrm{~K}$, proton irradiation results of Hudson \& Moore (1999) on $\mathrm{H}_{2} \mathrm{O}+\mathrm{CO}(5: 1)$ ice at $\sim 16 \mathrm{~K}$, and observed ratios in interstellar ices, comets, and the Orion hot core. The graph is based on Watanabe et al. (2004, Fig. 5), and shows increasing processing from right to left. Powers of 10 indicate the ice's estimated exposure time (in years) to either the $\mathrm{H}$ fluence in molecular clouds (Watanabe's data) or the $1-\mathrm{MeV} \mathrm{H}^{+}$ cosmic-ray fluence (Hudson's data).

Another route we examined for glycolaldehyde formation will apply when $\mathrm{CH}_{3} \mathrm{OH}$ exists in a CO-rich (apolar) ice. Figure 6 shows the IR spectrum of $\mathrm{CO}+\mathrm{CH}_{3} \mathrm{OH}$ (100:1) after radiolysis. In this ice, rupture of a $\mathrm{CH}$ bond gives an $\mathrm{H}$ atom that reacts with the $\mathrm{CO}$ matrix to make $\mathrm{HCO}$, with a subsequent radical-radical reaction between $\mathrm{HCO}$ and $\mathrm{CH}_{2} \mathrm{OH}$ giving glycolaldehyde. Two weak features in Figure 6 indicate the presence of $\mathrm{HOCH}_{2} \mathrm{C}(\mathrm{O}) \mathrm{H}$, as shown by our reference spectrum. Other products include the $\mathrm{HCO}$ radical, $\mathrm{H}_{2} \mathrm{CO}$, and $\mathrm{CH}_{3} \mathrm{C}(\mathrm{O}) \mathrm{H}$.

\subsection{Study of $\mathrm{C}_{2} \mathrm{H}_{2}$ in $\mathrm{H}_{2} \mathrm{O}$ Ices}

A second small, carbon-containing, unsaturated molecule we examined is acetylene $\left(\mathrm{C}_{2} \mathrm{H}_{2}\right)$. Acetylene forms in the photospheres of AGB stars where $\mathrm{C} / \mathrm{O} \gg 1$, locking up most of the elemental carbon. Gas-phase acetylene and its derivatives are thought to be the building blocks of PAHs and soot (e.g., Tielens \& Charnley 1997). When $\mathrm{C}_{2} \mathrm{H}_{2}$ is condensed into an icy grain mantle, however, $\mathrm{H}$-atom addition reactions are possible, culminating in $\mathrm{C}_{2} \mathrm{H}_{6}$ (Charnley et al. 1992, 1995). In fact, it was the detection of nearly equal abundances of $\mathrm{C}_{2} \mathrm{H}_{6}, \mathrm{C}_{2} \mathrm{H}_{2}$, and $\mathrm{CH}_{4}$ in Comets $\mathrm{C} / 1996$ B2 Hyakutake and C/1996 O1 Hale-Bopp that led Mumma et al. (1996) to point out that these cometary species did not originate in a thermochemically-equilibrated region of the solar nebula. Instead, the observed abundances were consistent with expected production of $\mathrm{C}_{2} \mathrm{H}_{6}$ in interstellar ices. Similar 


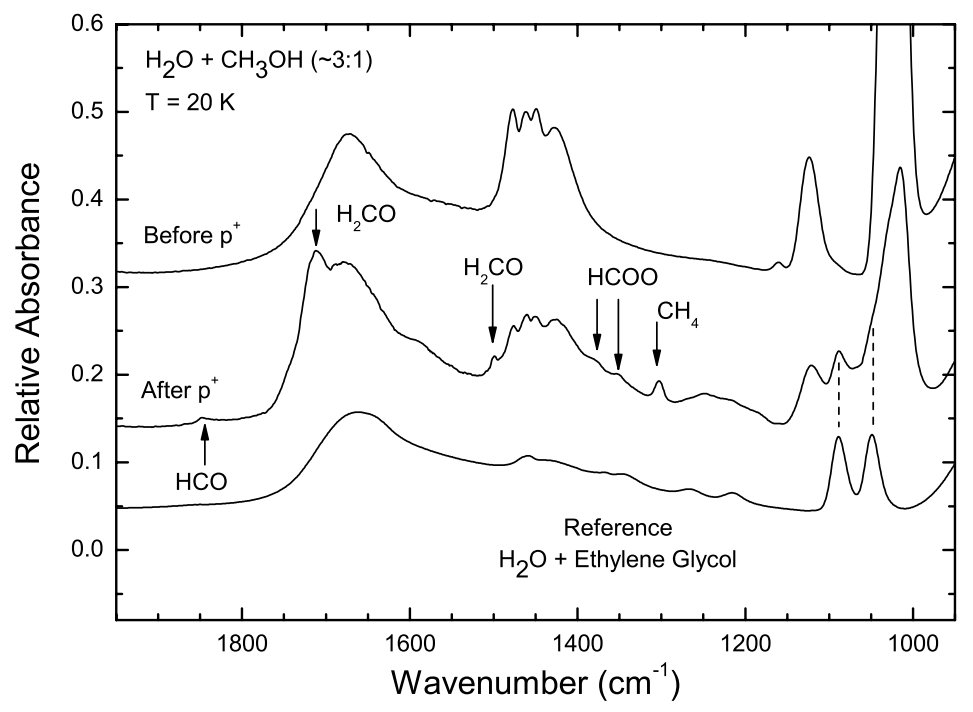

Figure 4. IR spectra of $\mathrm{H}_{2} \mathrm{O}+\mathrm{CH}_{3} \mathrm{OH}$ ice before (upper) and after (middle) an irradiation to $\sim 18 \mathrm{eV}_{\text {molecule }}^{-1}$ with $0.8 \mathrm{MeV}$ protons. New products include $\mathrm{H}_{2} \mathrm{CO}, \mathrm{CH}_{4}, \mathrm{HCOO}^{-}$, and ethylene glycol. At the bottom is a spectrum of unirradiated $\mathrm{H}_{2} \mathrm{O}+$ ethylene glycol for reference. Not shown are several other confirming bands for ethylene glycol between 500 and $1000 \mathrm{~cm}^{-1}$.

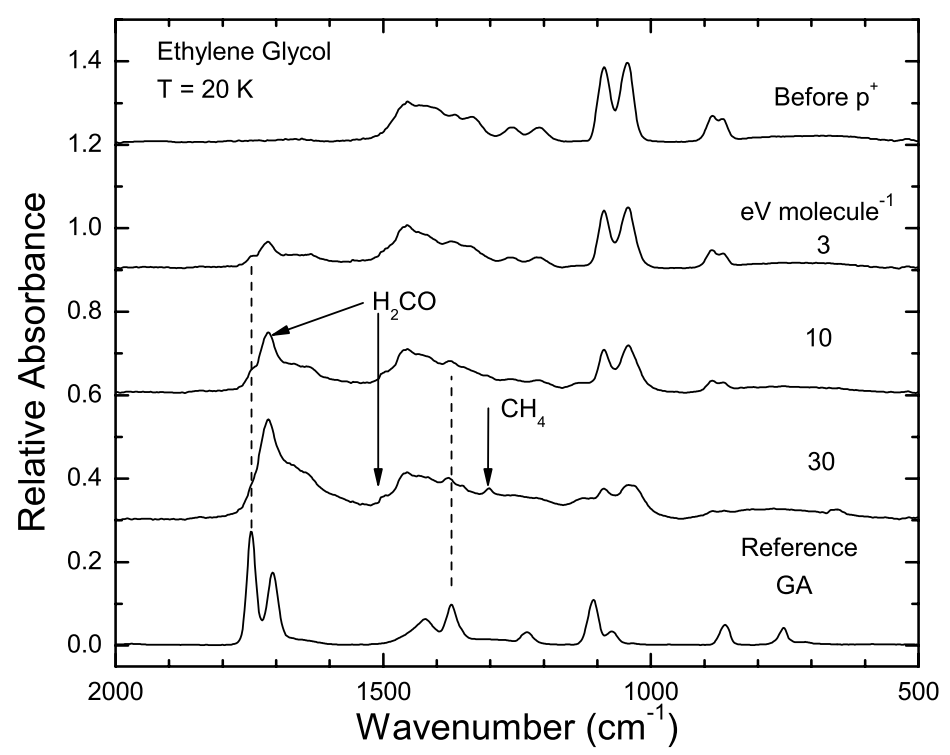

Figure 5. IR spectra of ethylene glycol before and after proton irradiation to a dose of $\sim 3,10$, and $30 \mathrm{eV}$ molecule ${ }^{-1}$ compared to a spectrum of glycolaldehyde (GA) at $20 \mathrm{~K}$.

abundances for these organic volatiles were also found in Comet Lee, 153P/Ikeya-Zhang, and 9P/Tempel-1 (post-impact); see Mumma et al. (2005) and references therein.

We have shown experimentally that radiation processing of $\mathrm{H}_{2} \mathrm{O}+\mathrm{C}_{2} \mathrm{H}_{2}$ ices forms $\mathrm{C}_{2} \mathrm{H}_{4}$ and $\mathrm{C}_{2} \mathrm{H}_{6}$ through $\mathrm{H}$ addition (Moore \& Hudson 1998) in the condensed phase. 


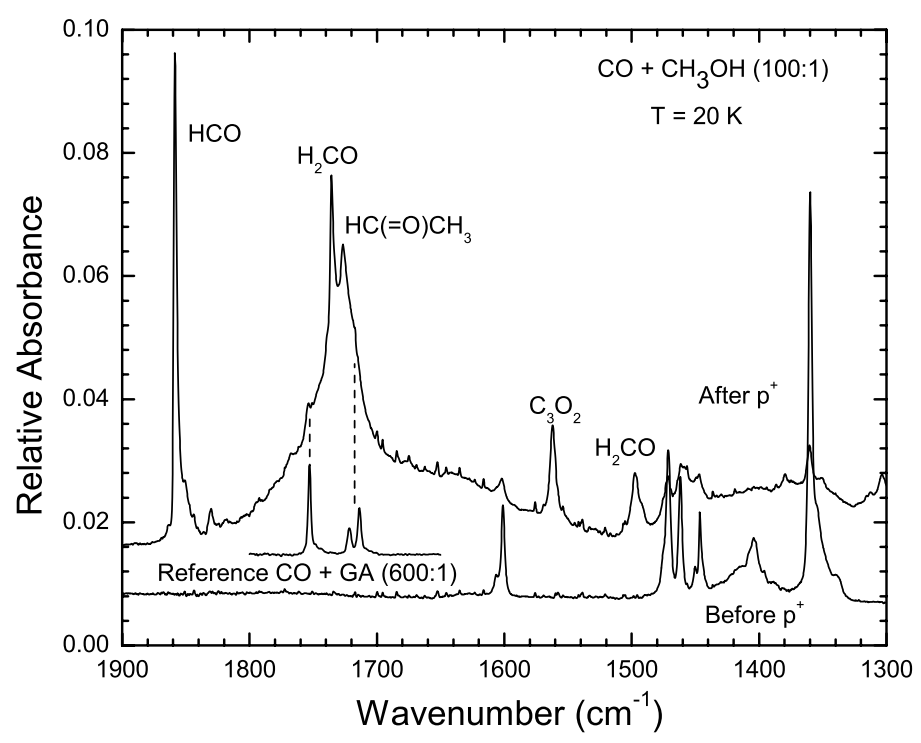

Figure 6. IR spectra of $\mathrm{CO}+\mathrm{CH}_{3} \mathrm{OH}(100: 1)$ before (lower) and after (upper) irradiation with $0.8 \mathrm{MeV}$ protons to a dose of $\sim 1 \mathrm{eV}^{\text {molecule }}{ }^{-1}$. A reference spectrum of $\mathrm{CO}+$ glycolaldehyde (GA) $(600: 1)$ is compared with weak features on the wings of the large $1730 \mathrm{~cm}^{-1}$ band.

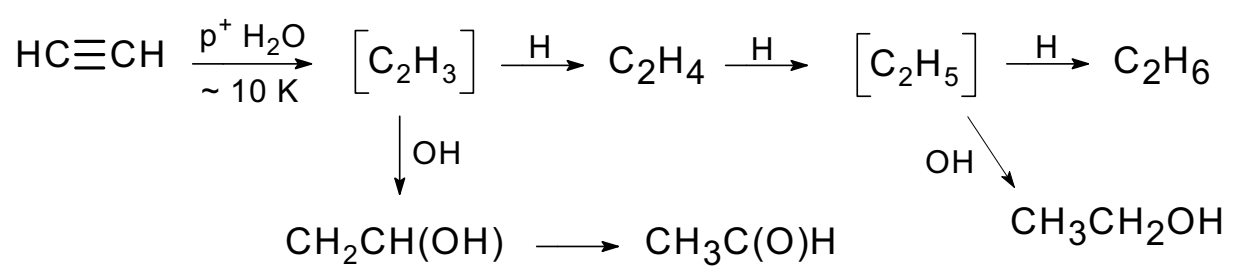

REACTION SCHEME 2

$\mathrm{CH}_{3} \mathrm{C}(\mathrm{O}) \mathrm{H}, \mathrm{C}_{2} \mathrm{H}_{6}, \mathrm{CH}_{2} \mathrm{CH}(\mathrm{OH})$, and $\mathrm{C}_{2} \mathrm{H}_{5} \mathrm{OH}$ form through the multi-step reactions seen in Reaction Scheme 2. In addition, both $\mathrm{CO}_{2}$ and $\mathrm{CO}$ are detected along with $\mathrm{H}_{2} \mathrm{CO}$. Figure 7 shows IR spectra of $\mathrm{H}_{2} \mathrm{O}+\mathrm{C}_{2} \mathrm{H}_{2}$ (4:1) at $20 \mathrm{~K}$ before and after a dose of $17 \mathrm{eV}$ molecule ${ }^{-1}$. Additional $\mathrm{C}_{2} \mathrm{H}_{6}$ absorptions at 2880, 2939, and $2975 \mathrm{~cm}^{-1}$ were stronger than the weak $1464 \mathrm{~cm}^{-1}$ band shown in this region, and aided in the spectral assignments. The identifications of the isomers vinyl alcohol and acetaldehyde, $\mathrm{CH}_{2} \mathrm{CH}\left(\mathrm{OH}\right.$ ) and $\mathrm{CH}_{3} \mathrm{C}(\mathrm{O}) \mathrm{H}$ respectively, are especially interesting (Hudson \& Moore 2003) as both are known interstellar molecules. Our experiments support the idea that a similar chemistry produces these molecules in interstellar space.

The abundance ratios of $\mathrm{CH}_{4}, \mathrm{C}_{2} \mathrm{H}_{6}$, and $\mathrm{C}_{2} \mathrm{H}_{2}$ in these experiments are sufficient to explain the cometary observations. Variables that did change the final abundances include the radiation dose, the dilution of $\mathrm{C}_{2} \mathrm{H}_{2}$ in the starting ice, and the initial presence of $\mathrm{CH}_{4}$ in the ice. Since we did not observe $\mathrm{C}_{2} \mathrm{H}_{2}$ formation in irradiated $\mathrm{H}_{2} \mathrm{O}+\mathrm{CH}_{4}$ mixtures, but did find $\mathrm{CH}_{4}$ formation in $\mathrm{H}_{2} \mathrm{O}+\mathrm{C}_{2} \mathrm{H}_{2}$ ices, we conclude that relevant 


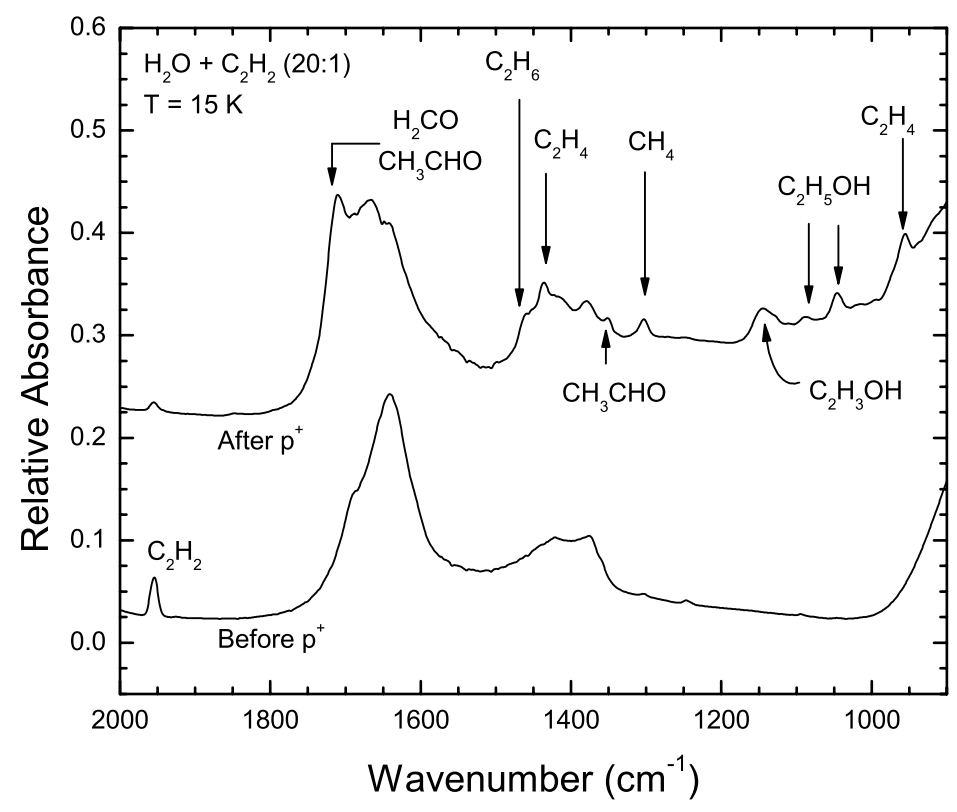

Figure 7. IR spectra of $\mathrm{H}_{2} \mathrm{O}+\mathrm{C}_{2} \mathrm{H}_{2}$ before and after irradiation to a dose of $17 \mathrm{eV}$ molecule ${ }^{-1}$. New products are identified by comparison with appropriate reference spectra (see Moore \& Hudson 1998).<smiles>C#CC=O</smiles>

REACTION SCHEME 3

hydrocarbon chemistry for these comets is founded on $\mathrm{H}$ addition to $\mathrm{C}_{2} \mathrm{H}_{2}$, as opposed to $\mathrm{CH}_{4}$ reactions. This suggests that $\mathrm{C}_{2} \mathrm{H}_{2}$ is part of the natal cometary ice composition.

In extrapolating these results to a more complex molecule, propynal $[\mathrm{HC} \equiv \mathrm{CC}(\mathrm{O}) \mathrm{H}]$, similar H-addition reactions are expected to form propenal and propanal. All three of these aldehydes have been observed in Sagittarius B2(N) (Hollis et al. 2004). The Hatom addition sequence connecting these molecules is expected to be that shown in Reaction Scheme 3. Although only the first three organics in Reaction Scheme 3 have been identified as interstellar, the conversion of aldehydes to alcohols is consistently found in our experiments. Therefore, we safely predict the conversion of propanal into $n$-propanol, and encourage observational searches for the latter.

\subsection{Study of $\mathrm{HCN}$ in $\mathrm{H}_{2} \mathrm{O}$ Ices}

A third unsaturated, carbon-containing molecule we examined is $\mathrm{HCN}$. This molecule is seen in the gas phase in the interstellar medium (e.g., Snyder \& Buhl 1971; Boonman et al. 2001) and in cometary comae (e.g., Ip et al. 1990; Bockelée-Morvan et al. 1994; Magee-Sauer et al. 1999). It is also thought that HCN is a native nuclear ice component in comets. The idea that HCN might participate in the chemistry of interstellar ices was the motivation for our experiments on $\mathrm{H}_{2} \mathrm{O}+\mathrm{HCN}$ ices (Gerakines et al. 2004). 


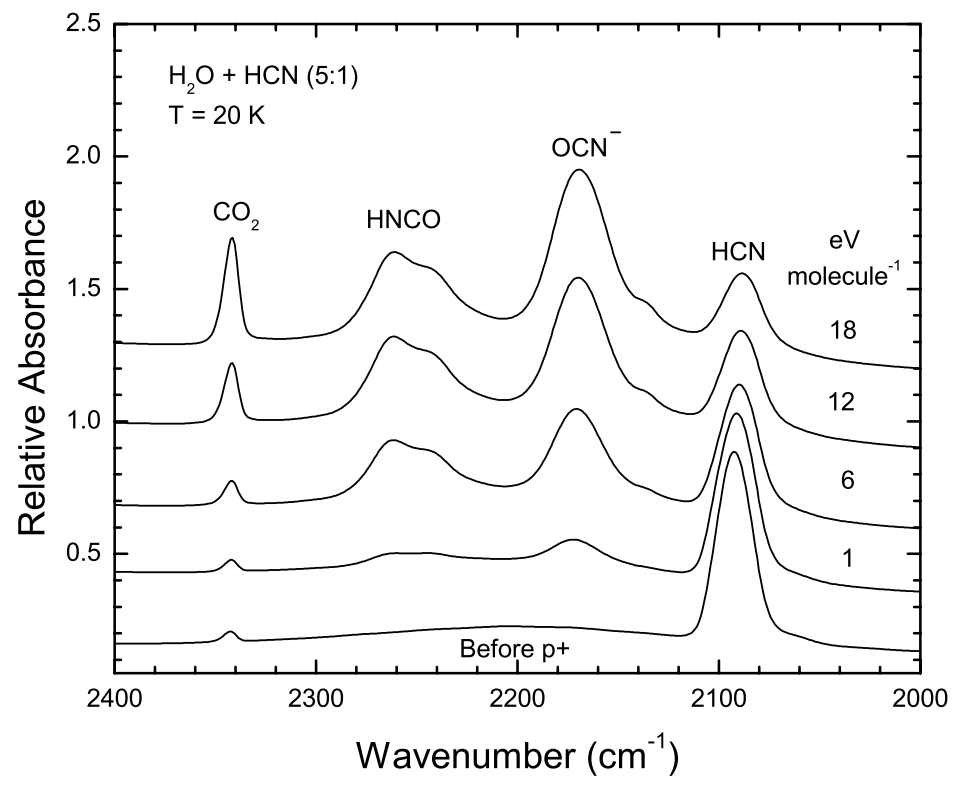

Figure 8. IR spectra of $\mathrm{H}_{2} \mathrm{O}+\mathrm{HCN}$ before and after irradiation to a dose of $\sim 1,6,12$, and $18 \mathrm{eV}$ molecule ${ }^{-1}$. New products include $\mathrm{HNCO}, \mathrm{OCN}^{-}$, and $\mathrm{CO}_{2}$.

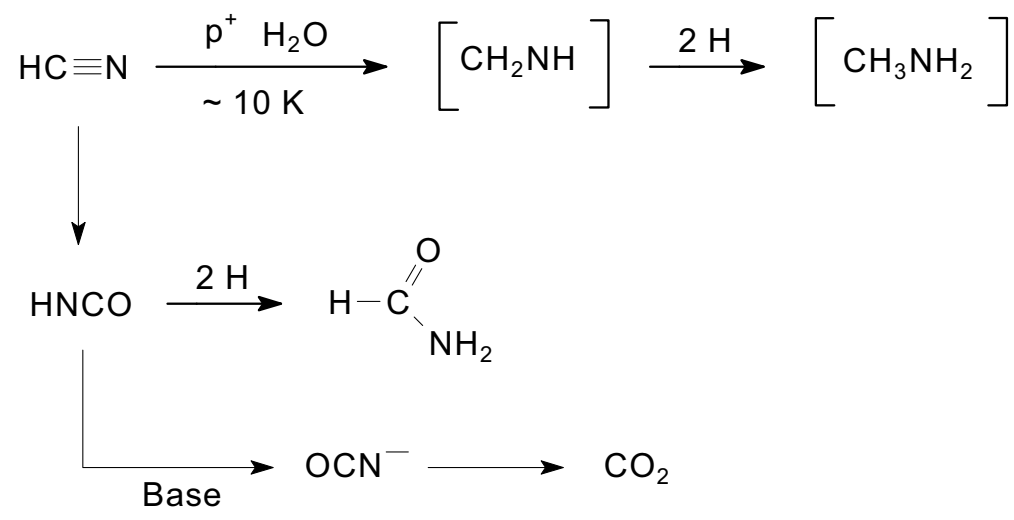

\section{REACTION SCHEME 4}

Solid-phase HCN reactions analogous to those with $\mathrm{CO}$ and $\mathrm{C}_{2} \mathrm{H}_{2}$ will result in methylenimine $\left(\mathrm{CH}_{2} \mathrm{NH}\right)$ and methylamine $\left(\mathrm{CH}_{3} \mathrm{NH}_{2}\right)$, both being IS gas-phase molecules. However, our experiments showed that oxidation products of $\mathrm{HCN}$ dominated the IR spectrum of $\mathrm{H}_{2} \mathrm{O}+\mathrm{HCN}$ ices after radiolysis. Figure 8 shows the $2400-2000 \mathrm{~cm}^{-1}$ region for $\mathrm{H}_{2} \mathrm{O}+\mathrm{HCN}(5: 1)$ at $18 \mathrm{~K}$ before and after several radiation doses (Gerakines et al. 2004). Identified products are the cyanate anion $\left(\mathrm{OCN}^{-}\right)$, isocyanic acid ( $\left.\mathrm{HNCO}\right)$, and $\mathrm{CO}_{2}$. Features in the $1800-1000 \mathrm{~cm}^{-1}$ region (not shown) were identified with the $\mathrm{NH}_{4}^{+}$ cation at $1470 \mathrm{~cm}^{-1}$ and formamide $\left(\mathrm{HCONH}_{2}\right)$ at both 1686 and $1386 \mathrm{~cm}^{-1}$. Steps leading to these products are shown in Reaction Scheme 4.

Although IS ices are dominated by $\mathrm{H}_{2} \mathrm{O}$, and neither $\mathrm{HCN}$ nor any organic nitrile has been identified in them, these ices often show an intense IR feature ascribed to $\mathrm{OCN}^{-}$ (Hudson et al. 2001). This observation of $\mathrm{OCN}^{-}$, as opposed to $\mathrm{HCN}$ and nitriles, can 
be understood from our experiments, since our work demonstrates the ease with which $\mathrm{OCN}^{-}$forms in $\mathrm{H}_{2} \mathrm{O}+\mathrm{HCN}$ mixtures. Morover, $\mathrm{HCN}$ is not the only possible source of cyanate, as subsequent irradiations of many nitriles in $\mathrm{H}_{2} \mathrm{O}$-ice all showed $\mathrm{OCN}^{-}$ formation (Hudson \& Moore 2004). This suggests that the cyanate ion may be a marker for energetic processing. Like $\mathrm{CO}_{2}$, the cyanate ion is a stable, linear, 16-electron species. It has been seen in warming experiments to $\sim 200 \mathrm{~K}$ (Moore \& Hudson 2003), and is predicted to be on the surfaces of outer solar system bodies.

HNCO, indicated in Figure 8, is detected only as a gas-phase species in both interstellar sources and comets (e.g., Gibb et al. 2000; Schutte \& Khanna 2003 and references therein). Its absence in IS ices suggests that it reacts to form $\mathrm{OCN}^{-}$and a counter-ion. Candidate bases include $\mathrm{H}_{2} \mathrm{O}$, formamide, and methylamine. More likely, HNCO combines with $\mathrm{NH}_{3}$ to make $\mathrm{OCN}^{-}$and $\mathrm{NH}_{4}^{+}$. In fact, features in several interstellar sources are attributed to $\mathrm{NH}_{4}^{+}$(Schutte \& Khanna 2003).

\section{Conclusions}

Our experiments demonstrate that several types of chemical reactions are involved in making complex molecules. In irradiated $\mathrm{H}_{2} \mathrm{O}$-rich ices containing $\mathrm{CO}$ or $\mathrm{C}_{2} \mathrm{H}_{2}, \mathrm{H}$ - and $\mathrm{OH}$ - additions produce many stable organics, some more oxidized than the reactants, and some more reduced. Radicals formed during irradiation can dimerize, thereby lengthening carbon chains. Examples include the dimerization of $\mathrm{CH}_{3}$ to form $\mathrm{C}_{2} \mathrm{H}_{6}$ (Moore \& Hudson 1998) and, more recently, the dimerization of $\mathrm{CH}_{2} \mathrm{OH}$ to make $\mathrm{HOCH}_{2} \mathrm{CH}_{2} \mathrm{OH}$ (Hudson et al. 2005). Current experiments involve studies of $2 \mathrm{CH}_{2} \mathrm{CN} \rightarrow\left(\mathrm{CH}_{2} \mathrm{CN}\right)_{2}$ in processed $\mathrm{H}_{2} \mathrm{O}+\mathrm{CH}_{3} \mathrm{CN}$. This is work in progress and relies on HPLC analysis of irradiated ice residues. It shows that identification of complex molecules are often at the limit of IR capabilities and require more-sensitive analytical techniques.

We have also found isomerization reactions help to explain the presence of isomeric pairs such as vinyl alcohol and acetaldehyde. Our work shows that vinyl alcohol is made in irradiated $\mathrm{H}_{2} \mathrm{O}+\mathrm{C}_{2} \mathrm{H}_{2}$, and then isomerizes to acetaldehyde. Among the nitriles, isomerizations include $\mathrm{HCN} \rightarrow \mathrm{HNC}$ and $\mathrm{CH}_{3} \mathrm{CN} \rightarrow \mathrm{CH}_{3} \mathrm{NC}$ (Hudson \& Moore 2004), and formation of ketenimines such as $\mathrm{CH}_{3} \mathrm{CN} \rightarrow \mathrm{H}_{2} \mathrm{C}=\mathrm{C}=\mathrm{NH}$. Extensions give a prediction of interstellar carbodiimide from cyanamide $\left(\mathrm{NH}_{2} \mathrm{C} \equiv \mathrm{N} \rightarrow \mathrm{HN}=\mathrm{C}=\mathrm{NH}\right)$ and allene from methylacetylene $\left(\mathrm{CH}_{3} \mathrm{C} \equiv \mathrm{CH} \rightarrow \mathrm{H}_{2} \mathrm{C}=\mathrm{C}=\mathrm{CH}_{2}\right)$.

Interconversions of aldehydes and alcohols are examples of both $\mathrm{H}$-atom addition and the reverse reaction (hydrogen elimination). Our work has included the following: $\left[\mathrm{H}_{2} \mathrm{CO}, \mathrm{CH}_{3} \mathrm{OH}\right],\left[\mathrm{CH}_{3} \mathrm{C}(\mathrm{O}) \mathrm{H}, \mathrm{CH}_{3} \mathrm{CH}_{2} \mathrm{OH}\right]$, and $\left[\mathrm{HOCH}_{2} \mathrm{C}(\mathrm{O}) \mathrm{H}, \mathrm{HOCH}_{2} \mathrm{CH}_{2} \mathrm{OH}\right]$. This chemistry is expected to apply to more-complex pairs such as $[\mathrm{HC} \equiv \mathrm{C}-\mathrm{C}(\mathrm{O}) \mathrm{H}$, $\left.\mathrm{HC} \equiv \mathrm{C}-\mathrm{CH}_{2} \mathrm{OH}\right],\left[\mathrm{H}_{2} \mathrm{C}=\mathrm{CH}-\mathrm{C}(\mathrm{O}) \mathrm{H}, \mathrm{H}_{2} \mathrm{C}=\mathrm{CH}-\mathrm{CH}_{2} \mathrm{OH}\right]$, and $\left[\mathrm{H}_{3} \mathrm{C}-\mathrm{CH}_{2}-\mathrm{C}(\mathrm{O}) \mathrm{H}, \mathrm{H}_{3} \mathrm{C}-\right.$ $\left.\mathrm{CH}_{2}-\mathrm{CH}_{2} \mathrm{OH}\right]$. Therefore, our experiments suggest that IS aldehyde-alcohol pairs are likely if either member participates in condensed-phase radiation chemistry.

In all cases, formation paths compete with dissociation and elimination processes that lead to less-complex molecules. Acid-base reactions can also play a role, particularly regarding the formation of ions. Altogether, the reactions examined lead to about $50 \%$ of the known stable IS organics containing oxygen, and most of those found in comets. These observations show that discovering the identities of and reactions paths for complex interstellar molecules will require a firm understanding of simpler systems.

\section{Acknowledgements}

NASA funding through the Planetary Atmospheres and SARA programs, and the Goddard Center for Astrobiology, is acknowledged. R.L.H. acknowledges the support of 
NASA for Grant NAG-5-1843. Claude Smith and Steve Brown are thanked for their work with the Van de Graaff accelerator at the Goddard Space Flight Center.

\section{References}

Allamandola, L.J., Sandford, S.A., \& Valero, G.J. 1988, Icarus 76, 225

Bockelée-Morvan, D., Padman, R., Davies, J.K., \& Crovisier, J. 1994, Planet. Space Sci. 42, 655

Boonman, A.M.S., Stark, R., van der Tak, F.F.S., van Dishoeck, E.F., van der Wal, P.B. Schäfer, F., de Lange, G., \& Laauwen, W.M. 2001, Ap. J. 553, L63

Bringa, E.M. \& Johnson, R.E. 2004, Ap. J. 603, 159

Charnley, S.B., Kress, M.E., Tielens, A.G.G.M., \& Millar, T.J. 1995, Ap. J. 448, 232

Charnley, S.B., Tielens, A.G.G.M., \& Millar, T.J. 1992, Ap. J. 399, L71

Crovisier, J., Bockelée-Morvan, D., Biver, N., Colom, P., Despois, D., \& Lis, D.C. 2004, A\&A 418, L35

Dickens, J.E., Irvine, W.M., \& DeVries, C.H. 1997, Ap. J. 312, 307

Federman, S.R. \& Allen, M. 1991, Ap. J. 375, 157

Gerakines, P.A., Moore, M.H., \& Hudson, R.L. 2004, Icarus 170, 204

Gibb, E.L., Whittet, D.C.B., \& Chair, J.E. 2001, Ap. J. 558, 702

Hiraoka, K., et al. 2005, Ap. J. 620, 542

Hiraoka, K., et al. 2002, Ap. J. 577, 262

Hollis, J.M., Lovas, F.J., \& Jewell, P.R. 2000, Ap. J. 540, L107

Hollis, J.M., Lovas, F.J., Jewell, P.R., \& Coudert, L.H. 2002, Ap. J. 571, L59

Hollis, J.M., Jewell, P.R., Lovas, F.J., Remijan, A., \& Møllendal, H. 2004, Ap. J. 610, L21

Hudson, R.L., Moore, M.H., \& Cook, A.M. 2005, Adv. Space Res. 36, 184

Hudson, R.L. \& Moore, M.H. 2004, Icarus 172, 466

Hudson, R.L. \& Moore, M.H. 2003, Ap. J. 586, L107

Hudson, R.L. Moore, M.H., \& Gerakines, P.A. 2001, Ap. J. 550, 1140

Hudson, R.L. \& Moore, M.H. 2001, JGR-Planets 106, 33275

Hudson, R.L. \& Moore, M.H. 2000a, Icarus 145, 661

Hudson, R.L. \& Moore, M.H. 2000b, A\&A 357, 787

Hudson, R.L. \& Moore, M.H. 1999, Icarus 140, 451

Ip, W.-H., et al. 1990, Ann. Geophys. 8, 319

Magee-Sauer, K., Mumma, M.J., DiSanti, M.A., Dello-Russo, N., \& Rettig, T.W. 1999, Icarus 142,498

Mehringer, D.M., Snyder, L.E., \& Miao, Y. 1997, Ap. J. 480, L71

Miao, Y. \& Snyder, L.E. 1997, Ap. J. 480, L67

Moore, M.H. \& Hudson, R.L. 2003b, Icarus 161, 486

Moore, M.H., Hudson, R.L., \& Ferrante, R.F. 2003a, Earth, Moon \& Planets 92, 291

Moore, M.H. \& Hudson, R.L. 2000, Icarus 145, 282

Moore, M.H., Hudson, R.L., \& Gerakines, P.A. 2001, Spectrochimica Acta 57, 843

Moore, M.H. \& Hudson, R.L. 1998, Icarus 135, 518

Mumma, M.J., et al. 2005, Science 310, 270

Mumma, M.J., DiSanti, M. A., Dello-Russo, N., Fomenkova, M., Magee-Sauer, K., Kaminski, C.D., \& Xie, D. X. 1996, Science 272, 1310

Nummelin, A., Dickens, J.E., Bergman, P. Hjalmarson, Å., Irvine, W.M., Ikeda, M., \& Ohishi, M. 1998, A\&A 337, 275

Okabe, H. 1978, Photochemistry of Small Molecules, Wiley, New York

Schutte, W.A. \& Khanna, R.K. 2003, A\&\&A 398, 1049

Snyder, L.E. \& Buhl, D. 1971, Ap. J. 163, L47

Teixeira, T.C., Emerson, J.P., \& Palumbo, M.E. 1998, A\& A 330, 711

Tielens, A.G.G.M. \& Whittet, D.C.B. 1997, in Molecules in Astrophysics: Probes and Processes, ed., E. F. van Dishoeck (Kluwer Academic Pub.), 45

Tielens, A.G.G.M. \& Charnley, S.G. 1997, in Origins of Life and Evolution of the Biosphere (Kluwer Academic Pub.), 23 
Tielens, A.G.G.M. \& Allamandola, L.J. 1987, in Interstellar Processes, eds. D. J. Hollenbach \&

H. A. Thronson (Reidel Pub., Dordrecht), 397.

Turner, B.E. \& Apponi, A.J. 2001, Ap. J. 561, L207

Watanabe, N., Nagaoka, A., Shiraki, R., \& Kouchi A. 2004, Ap. J. 616, L638

Watanabe, N., Shiraki, T., \& Kouchi, A. 2003, Ap. J. 588, L121

Ziegler, J.P., Biersack, J.P., \& Littmark, U. 1985, The Stopping and Range of Ions in Solids (Pergamon Press), New York, also see: http://www.srim.org/

\section{Discussion}

SCHLEMmER: The reaction schemes are written with neutral species. Protons induce electrons in the ice. Therefore the question is on the role of ions and excited species in the ice chemistry presented.

MoORE: In our proton-radiation experiments, the observed chemistry is dominated by reactions produced by secondary electrons. These electrons combine with a cation, producing free radicals such as $\mathrm{H}$ and $\mathrm{OH}$ that lead to the products we observe. In some cases, the electrons are sufficiently energetic to produce molecular excited states or bond dissociation. What we show in our paper are overall reaction sequences and not the mechanistic details.

BAURICHTER: How much UV light background do you have along with your ion beam coming out of your ion source?

MOORE: In our laboratory, the proton beam passes through a nickel metal foil before reaching our samples. This foil prevents any light from the proton beam tube from entering the ice chamber. The main purpose of the foil is to prevent samples from cryopumping contaminants from the vacuum system of the Van de Graaff accelerator.

HERBST: Would you consider modeling interstellar radiolysis chemistry based on your lab work? In the ISM, one must also worry about other processes such as a non-inert atmosphere?

Moore: We do get rates of processing as a function of radiation dose. For example, we can measure how much $\mathrm{CO}$ is left in an $\mathrm{H}_{2} \mathrm{O}+\mathrm{CO}$ ice after various doses, and we can measure column densities of new species produced. Since there are few alternatives to radiation processing for making many of the observed complex IS organics, data such as we present should be incorporated into models of IS chemistry. A knowledge of the expected cosmic-ray flux will be needed. 